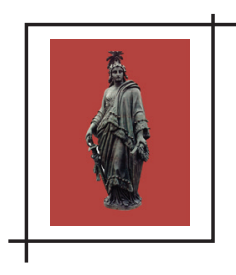

\title{
O CONCEITO DE LIBERDADE SEGUNDO THOMAS HOBBES
}

\author{
Marcelo Martins Bueno ${ }^{1}$ \\ "Não existe essa tal tranquilidade perpétua para a mente enquanto vivemos aqui; \\ porque a vida é apenas movimento, e nunca se pode estar sem desejo, nem sem \\ medo, muito menos sem uma sensação". Thomas Hobbes
}

Resumo: A presente reflexão examina a ideia de liberdade no universo de considerações da filosofia de Thomas Hobbes. Demonstra-se que o medo é resultado da igualdade dos homens vivendo em estado de natureza e que a liberdade se dá via criação do Estado (soberania), consequência do contrato, e o seu objetivo é a manutenção dos homens no estado civil, e, assim, entende-se o relevante papel que a filosofia política hobbesiana tem para a sociedade moderna. Trata-se da análise de uma teoria da soberania em que há uma preocupação com a liberdade dos cidadãos e não apenas um poder absoluto, como sempre foi interpretada.

Palavras-chave: Liberdade. Estado. Soberania. Medo. Contrato.

Thomas Hobbes, na primeira parte do De Corpore, Capítulo I, propõe que a função da filosofia é promover uma vida melhor para os homens, proporcionada pelas ciências no campo da filosofia prática, enquanto a filosofia moral é mais bem avaliada quando de sua ausência que acarreta as calamidades advindas das guerras.

Dividindo a filosofia em duas partes, Hobbes estabelecerá seu objetivo, pois entende que existem dois tipos de corpos bem distintos: o natural, que é obra da natureza, e o que é produto das vontades e do acordo entre os homens, chamado República. Surgem aí as partes da filosofia: natural e civil, esta última ainda subdividida em ética e política.

A intenção de Hobbes já está evidente com tais distinções, a saber: a filosofia natural e a geometria trouxeram para a humanidade uma vida mais confortável, pois desenvolveram técnicas fundamentais de domínio e conhecimento da natureza, proporcionando benefícios e comodidades. Já no campo da filosofia civil, não se atingiram tais objetivos, uma vez que, na história da humanidade, as guerras sempre estiveram presentes, evidenciando a falta de entendimento do que seria esse saber.

1 - Mestre e Doutor em Filosofia Política pela Pontifícia Universidade Católica de São Paulo (PUC/SP). Professor titular do Programa de Pós-Graduação em Educação, Arte e História da Cultura da Universidade Presbiteriana Mackenzie (UPM). E-mail: marcelo.bueno@mackenzie.br 
A preocupação da filosofia hobbesiana encontra nessa questão um ponto crucial de reflexão: quais motivos levam os homens às guerras e à morte? Seria por desconhecer suas causas? Embora saibam, pela experiência, que tudo isso é ruim, é maléfico para suas vidas, por que continuam a praticá-la?

Para Thomas Hobbes, a resposta está no fato de que os homens nunca foram ensinados suficientemente bem em como evitar tais problemas, ou melhor, nunca ensinaram as verdadeiras regras da vida em sociedade, porque nunca se teve um método verdadeiro, claro e objetivo sobre a filosofia moral e civil.

Diferentemente da filosofia natural e da geometria, cujos estudiosos desenvolveram um saber claro, exato e objetivo que não proporcionava controvérsias nos temas de que tratavam, ampliando a ciência e o desenvolvimento, a filosofia civil apresentava seus preceitos, na maioria das vezes, de acordo com o que Ihe conviesse, pois, seus estudiosos, na crítica de Hobbes, visavam a seus interesses, chegando até a estabelecer regras e preceitos como verdades universais, embora não o fossem. Eis o desafio de Thomas Hobbes: dar à filosofia civil o mesmo estatuto das ciências naturais, cujas verdades possam ser comprovadas e servir de suporte para a vida em sociedade sem os males da guerra e proporcionando o progresso.

Se a filosofia de Hobbes propõe uma sequência em que se vai do corpo ao homem e deste ao cidadão, é incontestável que afirme a necessidade de estudar o homem tanto como corpo natural quanto como corpo político. Quanto ao seu método, o autor já o estabelece no prefácio ao leitor da obra De cive: elementos filosóficos a respeito do cidadão:

Haveis visto qual é o meu método [e dividi-lo] [...] em três partes conforme o seu grau, pensava escrevê-los da seguinte forma: de modo que na primeira trataria do corpo, e de suas propriedades gerais; na segunda, do homem e de suas faculdades e afecções especiais; na terceira, do governo civil e dos deveres dos súditos. De modo que a primeira parte conteria a filosofia primeira, e certos elementos de física; nela consideraríamos as razões de tempo, lugar, causa, poder, relação, proporção, quantidade, figura e movimento. Na segunda discutiríamos a imaginação, a memória, o intelecto, o raciocínio, o apetite, a vontade, o bem e o mal, o que é honesto ou desonesto, e coisas parecidas. 0 que a última parte aborda é o que acabo de vos expor (HOBBES, 1998, p. 17-18).

Porém, ao traçar essa trilogia como proposta de trabalho, o autor invoca os acontecimentos políticos da Inglaterra setecentista, para na sequência fazer a seguinte afirmação: "Assim sucede que aquilo que era último na ordem veio a lume primeiro no tempo, e isso porque vi que esta parte, fundada em seus próprios princípios suficientemente conhecidos pela experiência, não precisaria das partes anteriores" (HOBBES, 1998, p. 18).

Ao deparar com uma afirmação tão categórica como a citada, tem-se a concepção inversa da anterior, pois o autor parece não deixar dúvidas quanto à independência da filosofia 
civil em relação à filosofia natural. Entende-se, assim, que, para Hobbes, mesmo aqueles que não compreendem as primeiras partes da filosofia, a saber, a geometria e a física, podem alcançar os princípios da filosofia civil, e na obra De corpore parece reforçar a tese:

\begin{abstract}
[...] uma vez que os principios da política resultam do conhecimento dos movimentos da mente, e que este conhecimento deriva da ciência das sensações e das ideias, mas ainda aqueles que não apreenderam a primeira parte da filosofia, a geometria e a física, podem, entretanto, chegar aos princípios da filosofia civil pelo método analítico (HOBBES, 2005, p. 74).
\end{abstract}

Com a afirmação do prefácio, entende-se que a intenção de Hobbes num primeiro momento era, segundo sua concepção metodológica, constituir argumentos que pudessem dar a ideia de dedução contínua em sua trilogia, a saber: a geometria, estabelecendo as bases da mecânica, está servindo para as verdades da física que serviria para os fundamentos da moral e da política. Ocorre que na prática a obra De cive (1642) precedeu em dezesseis anos a Do homem (1658) e a intenção de Hobbes foi totalmente alterada, uma vez que a obra De corpore só ficou pronta em 1655. Como o filósofo viveu mais de 90 anos, teve tempo suficiente para dar conta do seu propósito.

A novidade em sua filosofia está no fato de explicar todos os fenômenos mecânicos, igualando os processos físicos, biológicos e sociais ao funcionamento das máquinas. Explica o mundo corporal apelando para o jogo de movimentos, não fazendo diferença específica entre os corpos. Assim, o conceito de liberdade não fugirá à regra. Ora, mediante isso, podese notar a presença dos ideais da física nascente no pensamento do filósofo inglês e o conceito de liberdade que está relacionado a corpos e movimentos. A influência da Revolução Científica no pensamento hobbesiano pode ser percebida em quase toda a obra De corpore, na medida em que o filósofo inglês apresenta conteúdos destinados aos temas de mesma ordem e relevância para a ciência nascente.

Embora Hobbes raramente seja considerado um teórico essencial da ciência moderna, seus estudos, suas teorias, teses e seus experimentos de certa forma foram marcantes e influentes para um mundo em que a ciência dava seus primeiros passos. Aliás, vale destacar que Hobbes conseguiu dar conta do mundo material sem recorrer aos postulados teológicos, o que para a época era uma novidade e dava autonomia à ciência.

0 sistema filosófico de Hobbes, já imbuido desse espírito racionalista de seu tempo e, em seu caso particular, também materialista, se constitui de maneira que esses fundamentos servirão de alicerces para o seu pensamento. Para o filósofo inglês, essas noções fundamentais são as concepções de corpo e de movimento. Para sustentar sua tese de que a realidade é composta de corpos em movimento, Hobbes propõe-se a provar como um corpo em movimento age sobre outro. 
0 conceito de corpo é assim explicitado por Hobbes na parte II do De corpore:

Após o entendimento do que é o espaço imaginário, no qual supomos que nada permanece sem nós, exceto todas aquelas coisas a serem destruídas que, por existir, deixam imagens de si mesmas em nossas mentes, vamos agora supor que algumas delas devem ser colocadas no mundo ou criadas novamente. É necessário, assim, que esta nova criação ou reposição não preencha apenas algumas partes do espaço mencionado anteriormente, ou seja, coincidente e coextensa com ele, mas também que ele não tenha dependência de nosso pensamento. E isto é o que chamamos, normalmente, por extensão, de corpo; não depende do nosso pensamento, dizemos que ele subsiste de si próprio; como também existe, sem nós; e, por último, é chamado de sujeito, pois ele é tão bem colocado e sujeitado ao espaço imaginário que pode ser entendido pela razão, como também percebido pelos sentidos. A definição, assim, de corpo pode ser esta: um corpo é aquele que, não tendo dependência de nosso pensamento, é coincidente e coextenso com algumas partes do espaço (HOBBES, 1966, p. 101-102, tradução nossa).

A partir da definição de corpo, Hobbes mostrará como um age sobre outro provocando o movimento, definindo o papel de cada um nesse processo: "Assim, um corpo quando avança sobre outro, e nele provoca movimento, chama-se agente e o outro no qual o movimento é assim gerado chama-se paciente" (HOBBES, 1966, p. 120, tradução nossa).

Desses entrechoques de corpos, Hobbes definirá o efeito como sendo o acidente produzido no paciente e com isso caracterizará o movimento como uma relação de causalidade. As categorias de causalidade com as quais Hobbes trabalha são: causa eficiente e causa material, que servem de fundamentos para suas teorias, por exemplo: todas as coisas que existem (corpos) se encontram em um estado cinético qualquer, ou seja, o estado no qual um determinado corpo se encontra não advém de sua natureza específica, pois alguma força nele atuou como causa desse efeito.

Para exemplificar como se dá a transmissão do movimento, Hobbes parte da concepção de que todos os seres eram corporais e como estes existiam sempre em movimento eram sujeitos de todas as ações.

Para finalizar como se processa essa transmissão de movimento, Hobbes (1966) na III parte do De corpore, mais precisamente no capitulo XV que denomina "proporções dos movimentos e das grandezas", sugere que o leitor tenha em mãos os trabalhos de Euclides e Arquimedes, pois não teria sentido refazer o que estes já haviam feito; porém dará sua contribuição mesmo em não se tratando de algo novo.

Antes, porém, de realizar suas considerações acerca do movimento, Thomas Hobbes resgata a definição de seis importantes conceitos para o melhor entendimento desse processo, a saber: esforço, impetus, resistência, pressão, contrapressão e força. 0 conceito de esforço ou conatus nesta obra adquire uma característica bem peculiar. Entendido como uma carac- 
terística das paixões humanas em suas relações para a autopreservação, Hobbes dará aqui uma conceituação que está relacionada aos problemas estudados na época como movimento, espaço e tempo, e assim define:

Primeiro, defino esforço como sendo o movimento formado no menor espaço e no menor tempo dados, ou seja, menor do que possa ser determinado por exposição ou mensuração; ou seja, o movimento ocorre na duração de um ponto em uma determinada fração de tempo (HOBBES, 1966, p. 206, tradução nossa).

0 conceito de impetus é assim apresentado:

Segundo, defino impetus ou aceleração de um movimento como sendo a velocidade de um corpo em movimento, mas considerado em todos os pontos do tempo pelo qual ele se move. Neste sentido, impetus não é nada mais do que a quantidade ou velocidade do esforço. Mas, considerado todo o tempo, ele é toda a velocidade com a qual o corpo se move juntamente com todo o tempo e equivalente ao produto de uma linha que representa o tempo, multiplicada por uma linha que representa a média aritmética do impetus ou aceleração (HOBBES, 1966, p. 207, tradução nossa).

Esse conceito não apresenta novidades em relação ao já tratado anteriormente, na medida em que o identifica a uma força que pode ser maior ou menor, que atuará nos corpos fazendo-os acelerar, isto é, aumentar a velocidade; ou retardar; isto é, diminuir a velocidade. 0 terceiro conceito exposto por Hobbes é a resistência, que é a atuação de um corpo em sentido contrário ao movimento de outro.

Terceiro, defino resistência como o esforço de um corpo em movimento totalmente ou em parte contrário ao esforço de outro corpo também em movimento, os quais se tocam. Digo totalmente ao contrário, quando o esforço de dois corpos acontece na mesma linha reta provenientes de extremos opostos, e em parte contrário, quando dois corpos possuem o esforço em duas linhas, as quais procedem de pontos extremos de uma linha reta que igualmente se encontram (HOBBES, 1966, p. 211, tradução nossa).

Os conceitos a seguir são decorrentes do anterior e são denominados por Hobbes como pressão e contrapressão. Nesse sentido, e como ponto relevante, segue-se a citação:

Quarto, ocorre pressão quando dois corpos estão em movimento e um faz pressão sobre o outro quando estes possuem esforços, fazendo com que, total ou parcialmente, o outro corpo saia de seu local. 
Quinto, se um corpo é pressionado e não totalmente removido, ou seja, reintegrado a si mesmo, quando o corpo que o pressiona é retirado, as partes que são movidas fazem, pela razão da construção interna do corpo pressionado, retornar cada qual para o seu local (HOBBES, 1966, p. 211, tradução nossa).

Para ilustrar os dois últimos conceitos, Hobbes emprega o exemplo de elásticos mostrando que quando são pressionados, esticados por outros corpos, estes, por terem recebido uma força, modificam sua forma e tamanho; porém, quando se retira esse corpo que faz a pressão, os elásticos se restauram e voltam à forma anterior.

Por fim, definirá a força como sendo: [...] "o ímpeto ou velocidade do movimento multiplicado por ele mesmo ou pela grandeza do movimento, por meios onde o mesmo movimento funciona, mais ou menos, em relação ao corpo o qual Ihe oferece resistência" (HOBBES, 1966, p. 212, tradução nossa).

Para confirmar a importância de Hobbes na atividade científica setecentista, os conceitos expostos por ele refletem os principais temas tratados pelos cientistas e filósofos seus contemporâneos. 0 rigor e a precisão com que busca suas definições asseguram sua participação na nova ciência que começa a ser produzida.

As preocupações de Hobbes sobre o movimento são frutos dessas reflexões que se tornaram importantes para o desenvolvimento de todo seu trabalho. Com isso, após a definição de conceitos que julga essenciais para a retomada das discussões acerca do movimento, Hobbes o define como sendo a contínua privação de um local e a aquisição de outro pelos corpos.

Esse movimento deve ser considerado em três tempos, a saber: o passado, o presente e o futuro. Isso porque, para onde quer que o corpo se mova, não é para um ponto qualquer determinado, uma vez que esse movimento é constante, embora haja períodos de repouso, quando um corpo permanece por algum tempo em um lugar do plano onde o movimento ocorre; por isso a consideração em três tempos.

É por isso que, para Hobbes, o movimento pode ser mensurado por meio do tempo, haja vista que um corpo que se move, resultado de uma força nele aplicada, atinge uma certa velocidade que pode ser determinada pela linha do tempo, uma vez que percorre uma certa distância. Com isso, afirmava que os movimentos são equivalentes à velocidade, quando os tempos e as distâncias são correspondentes:

[...] movimentos podem ser considerados equivalentes quando a velocidade de um corpo em movimento comparada com toda parte de sua grandeza é equivalente à velocidade de um outro corpo, da mesma forma correspondente em todas as partes de sua grandeza. Por este motivo, pode-se perceber que movimentos equivalentes e movimentos de igual velocidade não possuem o mesmo significado; quando dois cavalos estão emparelhados, o 
movimento de ambos é maior do que o movimento de cada um separadamente; mas, a velocidade de ambos é igual à velocidade de cada um (HOBBES, 2005, p. 205).

Com tais definições e antes de ingressar especificamente no conceito de inércia, resultado dessas reflexões, Hobbes quer demonstrar que é por meio do movimento que sua filosofia se sustentará, porque movimento transmite movimento, gerando nos corpos uma cadeia constante e instantânea, pois um corpo em repouso move-se rapidamente ao ser por outro tocado, independentemente da força de um e da resistência do outro.

No Capítulo I da obra De corpore, a intenção de Hobbes era dar à ciência política as mesmas convicções de verdades da chamada filosofia natural, pois acreditava que, se os filósofos políticos tivessem desenvolvido suas teorias nos moldes dos geômetras, a vida em sociedade seria bem melhor, com paz e felicidade. Dai Hobbes desenvolver a tese das leis naturais como aquilo que se impõe à conservação da própria vida e, portanto, a paz que a condiciona. Não é por acaso que essa afirmação é apresentada como a primeira lei fundamental da natureza: "a lei de natureza primeira, e fundamental, é que devemos procurar a paz, quando possa ser encontrada; e se não for possivel tê-la, que nos equipemos com os recursos da guerra" (HOBBES, 1998, p. 38).

Porém, o conhecimento das regras civis ocorre diferentemente do mundo natural e, por isso, Hobbes, adepto que era da nova ciência e principalmente da física fundamentada na geometria, buscará incessantemente uma concepção de ciência política que se modele também nessa ciência, denominada filosofia natural. A afirmação de que na ciência, como nos teoremas, as verdades das consequências estão contidas nas proposições vale para todo tipo de conhecimento, sem exceções. É em virtude disso que, para Hobbes, a ciência civil é a ciência da paz, à semelhança da geometria. Ambas são concebidas como verdadeiras porque se dão por meio da quantidade e do movimento. Movimento esse que será utilizado na definição de liberdade.

Ao analisar o princípio da inércia, resultado das reflexões sobre o movimento no século XVII, nota-se que o conceito de liberdade proposto por Hobbes é resultado ou amolda-se a ele. Quando afirma na obra De corpore que um determinado corpo manterá seu estado cinético, ou seja, se estiver parado permanecerá nesse estado se não for deslocado por outro e, se estiver em movimento, continuará eternamente em movimento a não ser que outro corpo o detenha, é o próprio princípio que Hobbes está retomando das reflexões elaboradas por Descartes e principalmente por Galileu.

A concepção de liberdade parece partir desse princípio, pois, ao definir a liberdade como a ausência de impedimentos internos e externos, é ao princípio de inércia que o autor recorre, porque pressupõe que não haja obstáculos, ou seja, deverá haver um estado ideal para que isso ocorra e esse estado é, sem dúvida nenhuma, abstrato, em se tratando da dificuldade de comprovação do vácuo (vazio) no século XVII. 
0 recurso a um estado ideal para que se tenha uma ausência total de impedimentos é a concepção para a livre movimentação dos corpos. 0 que Hobbes está fazendo é naturalizando a liberdade, ou seja, submetendo-a à causalidade natural que significa não estar apenas nos domínios humanos, mas generalizada nos demais tipos de eventos. Tal concepção aliada ao materialismo agrega todos os ingredientes do mecanicismo de Hobbes, que são utilizados por ele para uma explicação ampla do mundo, quase uma completa cosmologia. É nesse sentido que a concepção de liberdade tem íntima ligação com o movimento do corpo humano, do homem enfim.

0 objetivo de Thomas Hobbes de dar à ciência política o mesmo estatuto das ciências naturais faz com que aplique a concepção de liberdade a tudo o que existe, não fazendo exceção às liberdades natural e civil que são objetos de reflexão da ciência política, porém, em se tratando de movimento e sua relação ao princípio da inércia cabe a seguinte reflexão: para Hobbes, os homens são livres enquanto seres corpóreos, isto é, dizer que alguém agiu livremente é afirmar que não houve qualquer impedimento interno ou externo para o desenvolvimento do seu movimento.

A esse respeito, observando as definições, a seguir, apresentadas por Hobbes, nota-se o conceito de liberdade tendo como paradigma as reflexões sobre o movimento, bem como o princípio da inércia recém-descoberto. Nas obras De cive e Leviatã, respectivamente, o conceito de liberdade é assim apresentado:

[...] a liberdade, podemos assim a definir, nada mais é que ausência dos impedimentos e obstáculos ao movimento; portanto, a água represada num vaso não está em liberdade, porque o vaso a impede de escoar; quebrado o vaso, ela é libertada. E todo o homem tem maior ou menor liberdade, conforme tenha mais espaço ou menos para si: como o que está numa ampla prisão é mais livre do que numa apertada. E um homem pode ser livre para um rumo e, contudo, não o ser para outro, assim como o viajante está aprisionado deste e daquele lado pelas cercas vivas ou muros de pedras (para que não estrague as vinhas ou o cereal) adjacentes à estrada. E estas espécies de impedimentos são externas e absolutas. Neste sentido, são livres todos os servos e súditos que não se encontram agrilhoados e aprisionados (HOBBES, 1998, p. 148-149).

[...] liberdade se entende, de acordo com o significado próprio da palavra, pela ausência de impedimentos externos, impedimentos que com frequência reduzem parte do poder que um homem tem de fazer o que quer; porém não podem impedir que use o poder que the resta, de acordo com o que seu juizo e razão Ihe ditem (HOBBES, 2003, p. 133).

Já o princípio de inércia está assim definido nas obras De corpore e Leviatã respectivamente: 
[...] quando um corpo está em repouso permanecerá neste estado, a não ser que outro corpo o desloque. E uma vez que esteja em movimento, sempre estará em movimento a não ser que haja outro corpo ao seu lado, que o detenha (HOBBES, 2005 p. 115).

Nenhum homem duvida da verdade da seguinte afirmação: quando uma coisa está imóvel, permanecerá imóvel para sempre, a menos que algo a agite. Mas não é tão fácil aceitar esta outra, que quando uma coisa está em movimento, permanecerá eternamente em movimento, a menos que algo a pare, muito embora a razão seja a mesma, a saber, que nada pode mudar por si só (HOBBES, 2003, p. 15).

Na filosofia hobbesiana o conceito de liberdade e o principio de inércia apresentam a ideia de obstáculo que impede o movimento. Em um sentido geral, a ausência de todos os tipos de impedimentos para a ação humana é o centro dessa reflexão, pois essa ideia está presente em ambos os conceitos. Em virtude disso, pode-se inferir que a definição de liberdade na filosofia de Thomas Hobbes tem como modelo a ciência setecentista nascente ou, mais precisamente, as reflexões acerca do movimento que desembocam no princípio de inércia. Assim, a autonomia que dá à filosofia política em relação à filosofia natural não será tão evidente quando a temática é a liberdade, haja vista que esta estará totalmente atrelada à concepção de movimento, ou seja, às novas descobertas da ciência nascente. Eis o ponto de partida de Thomas Hobbes para a conceituação de liberdade e sua possível e necessária conciliação com a soberania do Estado. A noção de liberdade tem, como se pode constatar, uma relação com a concepção dos movimentos dos corpos, na medida em que se pode afirmar que qualquer corpo, quando se encontra amarrado ou preso de um modo que não possa se mover, impedido pela oposição de outro corpo externo, não tem liberdade.

Dessa forma, é possivel entender que a liberdade para Hobbes significa a ausência de oposição e por isso definiu um homem livre como: "aquele que, naquelas coisas que graças a sua força e engenho é capaz de fazer, não é impedido de fazer o que tem vontade de fazer" (HOBBES, 2003, p. 133).

Hobbes, por ser um autor nominalista, não se deixa levar pelos valores retóricos que se atribuem às palavras. Conceitos como liberdade e igualdade são sempre recheados de muito entusiasmo e, por isso, os homens podem se deixar levar pelos seus amplos significados, podendo acarretar riscos para o contrato social e consequentemente para o Estado. Assim, entendendo o homem como um ser dotado de paixões, tanto em seu estado natural como civil, Hobbes elaborará o conceito de conato (conatus), isto é, o esforço ou empenho. Esse conceito é explicitado detalhadamente na obra Elementos de lei natural e política, em que afirma ser o movimento uma resposta do corpo ao estímulo recebido, que consiste no prazer e no desgosto, ou seja, é uma solicitação ou provocação para se aproximar do que agrada ou 
para se afastar do que desagrada, sendo essa solicitação o esforço primeiro ou começo interno do movimento animal.

0 conceito de conatus possui em sua estrutura genética informações básicas sobre os três movimentos que Hobbes trabalha, a saber: sensação, vital e voluntário. Esses pequenos inícios do movimento ou conatus, descritos como movimentos infinitesimais pertencentes a todas as criaturas vivas equipadas com a capacidade de animação, por serem internos nos seres vivos animados são dificeis de ser percebidos, o que não ocorre com aqueles tipos de ações visíveis, como andar, falar e lutar, que caracterizam os movimentos voluntários animados. Em síntese, sempre que uma ação visivel é pensada ou representada mentalmente, decorre de um trajeto posto em marcha por um objeto externo que aciona o aparelho perceptivo da criatura sensível, o qual envia uma informação sensivel que aciona a faculdade da imaginação e, enfim, origina-se uma solicitação ou provocação que consiste nesses conatus que se transformarão oportunamente em desejo ou aversão, conforme a avaliação empírico- cognitiva que o ser animado possui do objeto em questão, no que concerne à corroboração desse movimento que contém a vida. Constata-se, assim, uma intrínseca relação de causa e efeito entre a teoria do conhecimento e a teoria do movimento de Hobbes: o conatus se transforma em desejo ou aversão devido ao conteúdo empírico e sensível que orienta o comportamento a ser tomado.

Por meio do conceito de conatus, Hobbes identifica a origem da condição conflitiva humana e escolhe um mundo de representações na tentativa de contornar os problemas que daí surgem. De início, aponta toda impossibilidade da mudança dessa condição porque a natureza humana não muda, é a mesma em todo tempo e lugar, o homem será sempre um ser de movimentos, desejos e, por conseguinte, de uma surpreendente potencialidade conflitiva. Exemplificam os mais diversos conflitos pelos quais têm passado a história humana, a nossa condição psíquica, os eternos conflitos das relações de poder nas quais nos inserimos, bem como o caráter móvel dos nossos desejos e paixões.

Um impasse que surge nessa reflexão elaborada por Hobbes é o fato de que ao naturalizar tudo, inclusive o conceito de liberdade e submetê-lo a uma concepção mecanicista, como se poderá afirmar que o homem é livre na medida em que tudo está submetido a esse processo, ou seja, tudo é causalmente determinado? Para tentar solucionar tal impasse, Hobbes fará uma distinção entre deliberação e liberdade. Porém, para o entendimento desta, fez-se necessária uma análise das paixões humanas em que, para o autor, estão contidas as causas desse processo.

Hobbes expõe que nos animais existem dois tipos de movimentos. Os chamados vitais, que se iniciam no ser humano a partir do momento em que é gerado e o acompanham em toda a sua existência: circulação do sangue, pulsação, digestão, excreção etc. Os outros movimentos são chamados de voluntários, são eles: andar, falar, mover um dos membros. São provocados pelas sensações, iniciam-se a partir do que se vê, ouve ou sente, ou seja, pela ação dos 
movimentos dos corpos externos que entram em contato com as partes do corpo humano. Nesse processo tem-se também a imaginação, que é apenas a sensação diminuida, isto é, o resíduo desse mesmo movimento. Como os movimentos voluntários dependem de uma antecipação pela mente, Hobbes dirá que todos os movimentos voluntários têm suas origens internas na imaginação.

0 princípio dos movimentos existe de fato, embora às vezes os homens não consigam perceber, devido suas limitações, pois o que os move, ou o espaço em que se movem, é invisível ou muito pequeno, como ocorre internamente nos corpos, só são percebidos quando externados no andar, falar e nas ações visiveis; porém seu princípio está lá independentemente de nossas percepções. A esse processo Hobbes denominará conatus.

Trazendo novamente o conceito de conatus, apresentado por Hobbes na obra De corpore como um movimento dado no menor espaço e no menor tempo, que de tão rápido não possa ser mensurado, observam-se notadamente as reflexões sobre o movimento da nova ciência nesta conceituação e sobretudo o princípio de inércia, pois embora imperceptíveis, esses movimentos existem, a saber: os movimentos internos do corpo humano e alguns movimentos externos aos corpos. Ambos precisam da abstração para ser entendidos. Afirma Hobbes:

\footnotetext{
Porque um espaço nunca é tão pequeno que aquilo que seja movido num espaço maior, do qual o espaço pequeno faz parte, não deva primeiro ser movido neste último. Esses pequenos inícios do movimento, no interior do corpo do homem, antes de se manifestarem no andar, na fala, na luta e outras ações visiveis, chamam-se geralmente esforço (HOBBES, 2005, p. 36).
}

A concepção de Hobbes ao identificar o conatus como simplesmente uma paixão humana, ou seja, prazer e dor como resposta a uma solicitação ou provocação para aproximar-se do que agrada, ou retirar-se do que desagrada, aqui é explicitada mecanicamente e, para melhor compreensão, Hobbes lembra que não devemos considerá-lo como um ponto que não tenha quantidade e não possa ser dividido, uma vez que isso não existe na natureza, mas como algo cuja quantidade é irrelevante, ou seja, nem sua totalidade nem algumas de suas partes podem ser demonstradas pela experiência.

Aqui o pensador inglês está se referindo à experiência no sentido de comprovação, isto é, experiência bruta. Por algo não poder ser realizado, não se pode negar sua existência; esse ponto a que se refere não será tomado como indivisível, mas como algo não divisível, bem como o instante é tomado por um não tempo não dividido e não por um tempo indivisivel. Assim, o conatus é considerado como movimento, que não pode ser mensurado e nem demonstrado, mas existe.

Na consideração do conatus como expressão das paixões humanas, sua causa será chamada de Apetite, Desejo ou Aversão. 0 Apetite e o Desejo são a busca do ser humano para 
possuir um objeto, enquanto a Aversão é o esforço para mantê-lo afastado. Dessa forma, quando o objeto está próximo, denomina-se amor; e ódio, quando não se consegue afastá-lo. Assim, Hobbes lembra que a ideia de movimento está contida nessas duas palavras, que vêm do latim e significam movimento de aproximação e afastamento respectivamente. Presume-se a partir daí que Bom e Mau são determinados pelo que se quer perto ou longe, quer dizer, Bom é Apetite e Desejo daquilo que se quer perto e Mau é Aversão àquilo que se quer longe. A Depreciação é a ausência de apetite ou aversão de uma determinada coisa, sendo que essas questões de Bom, Mau e Depreciação estão sujeitas às avaliações dos homens, pois não procedem da natureza das coisas. A concepção de Depreciação também está relacionada ao movimento porque, para Hobbes, se não desejamos, nem odiamos determinados objetos, sentimos desprezo, ou seja, uma indiferença em relação a ele, ou melhor, uma imobilidade na medida em que não afeta o conatus. Tais avaliações nada mais são do que movimentos causados pelas ações dos objetos por meio das sensações, são apenas aparências, pois o efeito que causam, partindo dos órgãos dos sentidos, é o esforço, que consiste em Apetite ou Aversão pelo objeto, que se denomina Deleite ou Transtorno da Mente. Como a constituição do corpo humano está sempre em modificação, isto é, movimento, esses desejos, apetites e aversões podem também ser alterados em determinados momentos, ou seja, o que era aversão pode se tornar desejo e vice-versa.

Mas seja qual for o objeto do apetite ou desejo de qualquer homem, esse objeto é aquele a que cada um chama bom; ao objeto de seu ódio e aversão chama mau, e ao de seu desprezo chama vil e indigno. Pois as palavras bom, mau e desprezivel são sempre usadas em relação à pessoa que as usa. Não há nada que o seja simples e absolutamente, nem há qualquer regra comum do bem e do mal, que possa ser extraída da natureza dos próprios objetos. Ela só pode ser tirada da pessoa de cada um (quando não há Estado) ou então (num Estado) da pessoa que representa cada um; ou também de um árbitro ou juiz que pessoas discordantes possam instituir por consentimento, concordando que sua sentença seja aceite como regra (HOBBES, 2003, p. 37).

A análise que Hobbes faz referente ao movimento que se chama Apetite, que em sua manifestação é denominado Deleite ou Prazer, é a consequência do que é agradável e ajuda o fortalecimento dos movimentos vitais, enquanto as coisas que perturbam esses movimentos são chamadas de Molestas ou Ofensivas. Assim, a aparência do que é Bom denomina-se Prazer ou Deleite e a aparência do que é mau, Molestação ou Desagrado. Dessa forma: "todo apetite, desejo e amor é acompanhado por um deleite maior ou menor, e todo ódio e aversão por um desprazer e ofensa maior ou menor" (HOBBES, 2003, p. 38).

Alguns Prazeres ou Deleites são causados pela presença de objetos e são definidos, segundo Hobbes, como Prazeres dos Sentidos, visto que, ligados especificamente ao corpo, são 
agradáveis à visão, audição, olfato, gosto e tato. Sendo assim, os Prazeres da Mente que causam agrado são denominados Alegria. Na Molestação ou Desagrado sente-se aversão por objeto que possa provocar a dor, enfraquecendo ou perturbando os movimentos vitais, consequentemente gerando o medo e a tristeza. As paixões como Apetite, Desejo, Amor, Aversão, Ódio, Alegria e Tristeza são consideradas por Hobbes paixões simples porque, dependendo das considerações e relações, recebem outros nomes.

Na visão de Hobbes, o homem tem a faculdade de deliberar entre o fazer ou não fazer, de acordo com o seu apetite ou aversão, que são paixões que o inclinam à ação. No entanto, a vontade poderá determinar ações voluntárias, que são antes imaginadas na mente. A imaginação é o primeiro sinal interno de todos os movimentos voluntários, enquanto o princípio do movimento, antes de ser percebido em "ações visíveis", é chamado de esforço; tem-se a noção de conatus. Porém, quando esse conatus vem alternadamente no homem, gerando simultaneamente apetites, aversões, esperanças e medos, ou seja, provocando os atos de querer e não querer, traz consigo a indecisão, pois o homem, ao pensar nas diversas consequências possiveis de sua ação, que poderão ser boas ou más, se sente indefinido.

\begin{abstract}
Quando surgem alternadamente no espírito humano apetites e aversões, esperanças e medos, relativamente a uma mesma coisa; quando passam sucessivamente pelo pensamento as diversas consequências boas ou más de uma ação, ou de evitar uma ação; de modo tal que às vezes se sente um apetite em relação a ela, e às vezes uma aversão, às vezes a esperança de ser capaz de praticá-la, e às vezes o desespero ou o medo de empreendê-la; todo o conjunto de desejos, aversões, esperanças e medos, que se vão desenrolando até que a ação seja praticada, ou considerada impossivel, leva o nome de deliberação (HOBBES, 2003, p. 41).
\end{abstract}

A vontade distingue-se da inclinação, pois quando o homem tem vontade de fazer alguma coisa e não faz, significa inclinação e não ação voluntária. A vontade não se torna ação, mas a ação depende da inclinação, pois das inclinações nasce a vontade, ou seja, de todas as inclinações que vão afetando o homem, este, por meio da deliberação, encontra aquela que é sua vontade, mesmo que haja confusão em determinado momento em que a inclinação se torna apetite, determinando sua ação, portanto, sua vontade.

A ação de uma decisão pessoal é a vontade, o último apetite da deliberação que significa pôr um fim à liberdade que temos de realizar ou omitir de acordo com o nosso apetite ou aversão. Essa ação gera no homem um conflito, pois nesse momento pondera a respeito da ação que praticará, visto que nem sempre a ação escolhida é determinada pela sua vontade, pois pode ser levado à inclinação, não tendo certeza se será um deleite ou desagrado. Nota-se aqui a influência mecânica nesse processo, é a ideia de movimento que gera movimento na filosofia hobbesiana, bem como acontecia na ciência nascente. Assim, a deliberação não 
é racional, pois é chamada fim quando é tomada ou quando se chega à conclusão de que é impossivel. A razão difere da deliberação porque não termina na vontade, sua finalidade é a ciência, quer dizer, chegar às conclusões das causas e efeitos.

As ações voluntárias, portanto, nascem tanto dos apetites como das aversões, dependendo exclusivamente da vontade do homem que delibera sobre qualquer coisa que poderá considerar bem ou mal. Por isso, uma decisão tomada pelo medo poderá ser considerada uma ação livre, porque foi tomada mediante as ponderações de suas consequências.

Fica assim manifesto que as ações voluntárias não são apenas as ações que têm origem na cobiça, na ambição, na concupiscência e outros apetites em relação à coisa proposta, mas também aquelas que têm origem na aversão, ou no medo das consequências decorrentes da omissão da ação (HOBBES, 2003, p. 42).

Por fim, o importante é entender a relação que Hobbes fará entre a ação, a vontade e a liberdade: a ação estará sempre de acordo com a vontade, ou seja, a ação revela a vontade do indivíduo. Tem-se, assim, em Hobbes, a concepção de que ninguém poderá agir contra sua vontade, pois em um processo mecânico o efeito é sempre resultado de uma causa.

Nessa perspectiva, se alguém agiu motivado pelo medo ou pela confiança em sua força, igualmente agiu de acordo com sua vontade. Para Hobbes, não é possível agir contra sua vontade ou agir forçado porque toda deliberação é resultado do processo pelo qual o indivíduo ponderou sobre os sentimentos antagônicos em relação às possíveis consequências de sua decisão; porém, determinada a vontade, isto é, a causa da ação, a liberdade que ocorre nesse tempo de ponderação chega ao fim. A vontade é o último momento nesse processo de desejos e aversões; é dela que provém a ação, porém, quando ela ocorre, já não há mais liberdade. Durante o período de ponderação, o homem recorre à experiência acumulada por meio da memória, antecipando a ação no pensamento, de modo que a experiência o fará evitar a repetição daquilo que para ele foi desagradável.

Assim, como deliberar constitui uma escolha, essa sempre se dará visando à satisfação de preferências e desejos como expectativas positivas, uma vez que todo ser esforça-se no sentido daquilo que é próprio a Ihe conservar a vida e a torná-la viável, preferencialmente de forma confortável, ou seja, agradável. Quanto à liberdade, que Hobbes define como a ausência de impedimentos, só é possível aos corpos, pois são estes que estão sujeitos ao movimento. Os homens são livres enquanto seres corporais e, assim, não há atos voluntários contra a razão.

0 materialismo mecanicista da filosofia hobbesiana ajudará a compreensão desse processo, a saber: a liberdade é uma propriedade da ação cuja eficiência será considerada e toda ação eficiente é a ação de um corpo em movimento. Há, assim, três pontos fundamentais: a causalidade considerada é a eficiente, o mecanicismo e o materialismo. Desse modo, as 
paixões, enquanto resultado dos movimentos, podem ser relacionadas às leis mecânicas da natureza, uma vez que, pelo movimento, os objetos afetam as sensações e essas, numa relação causal, levam ao movimento vital, que por sua vez leva ao apetite e às demais paixões humanas. É esse processo mecânico que será utilizado por Hobbes para a compreensão dos movimentos de todos os corpos naturais, inclusive o homem, isto é, tendo como fundamento a concepção de movimento inercial, a saber: todos os corpos existem sempre em movimento e o repouso é apenas um instante em que os corpos são impelidos pela força maior de outro corpo, procurando demonstrar que a vida do homem não é mais do que movimentos de seus membros, mas, por ser dotado de razão, poderá, por meio desta, realizar cálculos e fazer a previsão de eventos futuros. Nesse aspecto, pode-se afirmar que não há uma base moral para sua filosofia, pelo contrário, nesse mecanicismo proposto fundamenta-se a amoralidade do seu pensamento.

Assim, essa concatenação de movimentos mecânicos é uma necessidade causal que, para Hobbes, não diminui sua natureza racional, já que compreende no mecanicismo a única explicação racional do mundo, no corpo e no movimento os dois únicos princípios de explicação, não reconhecendo outras realidades fora deles.

A compatibilidade entre a liberdade e a necessidade se dá por meio deste processo e é assim entendida: toda causa eficiente é ela mesma causada, pertencendo a uma cadeia causal e contínua, isto é, uma rede de causalidade que, se mergulhada na sua origem, levará à noção de Deus.

\footnotetext{
[...] Pois aquele que de qualquer efeito que vê ocorrer infira a causa próxima e imediata desse efeito, e depois a causa dessa causa, e mergulhe profundamente na investigação das causas, deverá finalmente concluir que necessariamente existe (como até os filósofos pagãos confessavam) um primeiro motor. Isto é, uma primeira e eterna causa de todas as coisas, que é o que os homens significam com o nome de Deus (HOBBES, 2003, p. 70).
}

Vale destacar que na filosofia hobbesiana a referência a esta causa primeira é no sentido aristotélico, apenas em termos mecânicos, pois como se sabe, para Aristóteles o movimento natural, é teleológico, ou seja, é a atualização do que é em potência. No caso de Hobbes, o movimento é apenas mudança de lugar, sem qualquer relação teleológica: os movimentos dos homens que se dão na busca de benefícios almejados e não na direção da atualização de sua essência são exclusivamente por efeito de causas eficientes.

Segue-se assim que, enquanto para Aristóteles a causa eficiente é necessária para explicar o movimento, porém é insuficiente, porque a causa deste é a causa final; isso para Hobbes não ocorre, aliás, das quatro causas aristotélicas, reconhece apenas a eficiente e a material, porque o movimento para ele é explicado unicamente pela causa eficiente, não havendo espaço para a causa final. Na filosofia hobbesiana, a causa eficiente e material são partes de 
uma causa inteira e juntas produzem um efeito: a causa eficiente, enquanto agregado de acidentes no agente, necessários para a produção do efeito; a causa material, enquanto agregado de acidentes no paciente, necessários para a produção do efeito. Já as causas formal e final são o mesmo que a eficiente, por isso Hobbes, mais uma vez na crítica a Aristóteles, entende que este apenas utiliza outros nomes à mesma coisa: "os escritores de metafísica enumeram outras causas além da eficiente e material, qual seja, a Essência, que alguns chamam de causa formal, e o Fim, ou causa final; as quais são, entretanto, causas eficientes" (HOBBES, 1966, p. 131, tradução nossa). Dessa forma, toda ação humana livre ou não, que é apenas o efeito considerado, é resultado deste encadeamento necessário de causas e efeitos, e essa ação, como efeito, cumpre necessariamente a causa primeira que não é por nada impedida. A definição de liberdade assim estabelecida é compatível com a mais estrita necessidade, pois, sendo considerada como movimento de um corpo, isto é, oposta ao repouso, a faculdade subjetiva da vontade está necessariamente a serviço da liberdade objetiva de querer ou não realizar determinadas ações.

[...] tal como as águas não tinham apenas a liberdade, mas também a necessidade de descer pelo canal, assim também as ações que os homens voluntariamente praticam, dado que derivam de sua vontade, derivam da liberdade; ao mesmo tempo que, dado que os atos da vontade de todo homem, assim como todo desejo e inclinação, derivam de alguma causa, e essa de uma outra causa, numa cadeia contínua (cujo primeiro elo está na mão de Deus, a primeira de todas as causas), elas derivam também da necessidade. De modo tal que para quem pudesse ver a conexão dessas causas a necessidade de todas as ações voluntárias dos homens pareceria manifesta (HOBBES, 2003, p. 134).

Para Hobbes, tal compatibilidade ocorre porque o homem quer o agir e não o querer. A vontade, enquanto ação, equivale à deliberação. Assim, um homem é livre para realizar a ação que projeta quando não se depara com nenhum impedimento, mesmo que sua vontade tenha infinitas causas. Os animais, por exemplo, deliberam porque também têm vontades; assim como nos homens, essas ações são resultados do querer voluntário em e por si mesmo, isto é, os desejos necessários para a vida como a fome, a sede, os apetites sensíveis, entre outros.

Na filosofia hobbesiana, a concepção de liberdade pode ser estendida a tudo que existe. As definições de liberdade natural e civil também vêm ao encontro dos ideais dos movimentos, emergidos no século XVII, bem como do conceito de inércia na medida em que um homem é considerado livre quando não encontra impedimentos à sua ação, se alguém age livremente é porque não encontra qualquer obstáculo interno ou externo para o desenvolvimento de sua ação, corroborando a ideia de que todos os corpos mantêm seu estado cinético (repouso ou movimento) a não ser que outros corpos os façam mudar. 
Pode-se concluir, portanto, que a liberdade se torna também um ponto de reflexão para o autor. A evolução do conceito nos seus escritos políticos requer que se apresentem, até mesmo de forma descritiva, as principais características dos homens vivendo nos dois estados apresentados por ele, antagônicos justamente pelo fato de apresentarem concepções distintas do conceito de direito, porque é a partir deste que o conceito de liberdade será decorrente. No estado de natureza todos os homens podiam tudo, isto é, existia uma falsa liberdade; no estado de sociedade a lei será a garantia da liberdade. Dessa forma, entende-se o interesse de Hobbes em tentar modelar as leis, ou melhor, a filosofia moral e politica nos rigores das ciências exatas, pois só assim ter-se-ia a convicção de que a paz e a liberdade não seriam ameaçadas, uma vez que, tendo como fundamentos a matemática e a geometria, a organização social seria garantida pelos Estados sem a necessidade de recorrer à imposição do poder por meio do medo:

Porque mesmo que em todos os lugares do mundo costumassem construir sobre a areia as fundações de suas casas, daí não seria possivel inferir que é assim que deve ser feito. 0 talento de fazer e conservar Estados consiste em certas regras, tal como a aritmética e a geometria (HOBBES, 2003, p. 127).

Assim, para Hobbes (2005), a liberdade pode ser vista de formas diferentes, a saber:

1. A liberdade que impera no estado de natureza, uma vez que os homens não se respeitam, ou melhor, respeitam apenas seus desejos particulares, independente do ônus que possa lhe causar o desejo alheio. E isso resulta em conflito de todos contra todos.

2. A liberdade que diz respeito ao direito de ir e vir. Ou seja, aquela liberdade que não aprisiona o homem. Para Hobbes, o homem já desfruta dessa liberdade.

3. A liberdade que permite ao homem, rodeado pelas leis, clamar por mais "liberdade". E no que diz respeito a esse tipo, o autor mostra que o Estado deve estar pronto para punir com a força aqueles que tentarem se contrapor às regras. Nesse caso, o resultado mais trágico é um retorno ao estado de natureza.

4. A liberdade que se relaciona às leis naturais que, casualmente, sejam desrespeitadas pelas leis artificiais, sobretudo no caso de levar o homem a atentar contra a sua própria vida, que é seu maior direito. Nesse caso, o homem tem a liberdade de voltar-se contra o soberano e lutar pela sua sobrevivência.

5. A liberdade do soberano, que é a maior de todas as liberdades. Para Hobbes, em trecho Do Cidadão, a diferença entre um súdito livre e um servo está no fato de que é verdadeiramente livre quem serve apenas a sua cidade, enquanto é servo aquele que também serve quem como ele é súdito. Toda outra liberdade é uma isenção das leis da cidade e convém apenas àqueles que detêm o poder. Ou seja, o súdito obedece de acordo com as regras, mas o soberano faz as regras e age de acordo com o que considera ideal. 
Até aqui, pode-se perceber o que Hobbes entende por liberdade e porque, e em nome de que, o homem deve abrir mão da plenitude do termo, pois para ele a liberdade está na vida civil. 0 homem é livre quando está submetido ao Estado, ou seja, às leis. É por isso que, para o autor, a soberania não reside nem na pessoa natural do monarca, nem em uma associação de pessoas naturais, mas na pessoa artificial do Estado. Autorizados pelos súditos, aqueles que conduzem essa pessoa artificial são os que detêm legitimamente o poder soberano, isto é, são autoridades; é justamente aqui que está a liberdade de todos.

É nessa perspectiva que se pode afirmar que o autor não é avesso às garantias das liberdades individuais. 0 seu projeto de um Estado forte que de fato agisse representando a vontade geral, isto é, não realizasse a vontade dos indivíduos, mas a vontade da unidade dos indivíduos, perdeu espaço para o culto ao individualismo, em detrimento do outro e até mesmo do próprio Estado, que foi reduzido a uma simples interpretação de um poder totalitário. Antecipando e prevendo tais conclusões, Thomas Hobbes distingue o estado do medo do estado de liberdade, que é a vida em sociedade.

É fato que todo homem, fora do estado do governo civil, possui uma liberdade mais completa, porém estéril: porque, se devido a esta liberdade alguém pode fazer de tudo a seu arbitrio, deve porém, pela mesma liberdade, sofrer de tudo, devido a igual arbítrio dos outros. Já numa cidade constituida, todo súdito conserva tanta liberdade quanto Ihe baste para viver bem e tranquilamente, e dos outros se tira o que é preciso para perdermos o medo deles. Fora deste estado, todo homem tem direito a tudo, sem que possa desfrutar, porém, de nada; neste estado, cada um pode desfrutar, em segurança, do seu direito limitado. Fora dele, qualquer homem tem o direito de espoliar ou de matar outro; nele, ninguém o tem, exceto um único. Fora do governo civil, estamos protegidos por nossas próprias forças; nele, pelo poder de todos. Fora dele, ninguém tem assegurado o fruto de seus labores; nele, todos o têm garantido. Finalmente: fora dele, assistimos ao domínio das paixões, da guerra, do medo, da miséria, da imundicie, da solidão, da barbárie, da ignorância, da crueldade; nele, ao domínio da razão, da paz, da segurança, das riquezas, da decência, da sociedade, da elegância, das ciências e da benevolência (HOBBES, 1998, p. 155-156).

Nesse intuito, pode-se afirmar que algumas interpretações de que Thomas Hobbes é avesso às liberdades e garantias individuais são fruto de leituras menos rigorosas de sua obra, pois para o autor há a possibilidade de se ter liberdades no Estado instituído, ou seja, Estado e liberdade podem ser compatíveis. Partindo-se de uma leitura mais rigorosa das suas principais obras, é possível mostrar que o Estado será fruto da própria escolha humana, sendo, dessa forma, resultado da própria racionalidade e que a forma absoluta se refere exclusivamente à ideia de soberania, sem a qual as liberdades e garantias individuais não seriam 
possiveis. Nesse sentido, entende-se por que Thomas Hobbes dedicou grande parte de sua vida a um tema dessa magnitude.

\title{
The concepto of freedom according to Thomas Hobbes
}

\begin{abstract}
The present reflection examines the idea of freedom in the universe of considerations of Thomas Hobbes philosophy. Fear is shown to be the result of the equality of men living in a state of nature, and that freedom is via the creation of the state (sovereignty), a consequence of the contract, and its purpose is to maintain men in civil status, and, Thus we understand the relevant role that Hobbesian political philosophy plays for modern society. It is the analysis of a theory of sovereignty where there is a concern for the freedom of citizens and not just absolute power, as has always been interpreted.
\end{abstract}

Keywords: Freedom. State. Sovereignty. Fear. Contract.

\section{REFERÊNCIAS}

ARISTÓTELES. Ética a nicômaco. Tradução Leonel Vallandro e Gerd Bornheim da versão inglesa de W. D. Ross. São Paulo: Abril Cultural, 1979. (Coleção Os Pensadores).

ARISTÓTELES. Física l e II. Tradução L. Angioni. Campinas: Unicamp, 1999. (Textos didáticos, ก. 34).

ARISTÓTELES. Politica. Tradução Roberto Leal Ferreira. 3. ed. São Paulo: Martins Fontes, 2006.

DESCARTES. El mundo. Tratado de la luz. Edición, introducción, traducción y notas Salvio Turró. Barcelona: Anthropos, 1989.

DESCARTES. Los princípios de la filosofia. Introducción, traducción y notas de Guilhermo Quintás. Madrid: Alianza Universidad, 1995.

DESCARTES. Meditações metafísicas. Obra escolhida. Tradução Bento Prado Júnior e J. Guinsburg. São Paulo: Difusão Europeia do Livro, 1962.

GALILEU GALILEI. Diálogo sobre os dois máximos sistemas do mundo ptolomaico e copernicano. Tradução, introdução e notas Pablo Rubén Mariconda. São Paulo: Discurso Editorial, 2004.

HOBBES, T. Behemoth ou o longo parlamento. Tradução Eunice Ostrensky. Prefácio e revisão técnica da tradução Renato Janine Ribeiro. Belo Horizonte: UFMG, 2001.

HOBBES, T. De cive: elementos filosóficos a respeito do cidadão. Tradução Renato Janine Ribeiro. São Paulo: Martins Fontes, 1998. 
HOBBES, T. De Corpore. Parte I: computação ou lógica). Tradução e notas José Oscar de Almeida Marques. Campinas: IFCH/Unicamp, 2005. (Clássicos da Filosofia. Cadernos de Tradução 12).

HOBBES, T. Diálogo entre um filósofo e um jurista. Tradução Maria Cristina Guimarães Cupertino. Prefácio de Renato Janine Ribeiro. 2. ed. São Paulo: Landy, 2004.

HOBBES, T. Elementos do direito natural e político. Tradução Fernando Couto. Porto: RÉS, 1993a. (Coleção Resjurídica).

HOBBES, T. Elements of philosophy. Concerning body. The english works of Thomas Hobbes de Malmesbury. Edited by W. Molesworth. 2. reimp. London: John Bohn, 1966.

HOBBES, T. Leviatã ou matéria, forma e poder de um estado eclesiástico e civil. Organizador Richard Tuck. Tradução João Paulo Monteiro, Maria Beatriz Nizza da Silva e Cláudia Berliner. Revisão da tradução Eunice Ostrensky. São Paulo: Martins Fontes, 2003. (Clássicos Cambridge de filosofia política).

HOBBES, T. Man and citizen (De homine and de cive). De Homine, translated by Charles T. Wood, T. S. K. Scott-Craig, and Bernard Gert, De Cive. Translated by Thomas Hobbes. Indianapolis: Hackett Publishing Company, 19936.

HOBBES, T. The english works of Thomas Hobbes. Edited by W. Molesworth. London: 1839.

HOBBES, T. Tratado sobre el cuerpo. Introducción, traducción y notas Joaquín Rodríguez Feo. Madrid: Trotta, 2000. (Clásicos de la Cultura).

Recebido em julho de 2018. Aprovado em outubro de 2018. 